\title{
STUDIES ON SPERM CAPACITATION
}

\section{THE RELATIONSHIP BETWEEN A GUINEA-PIG SPERM-COATING ANTIGEN AND A SPERM GAPACITATION PHENOMENON}

\section{S. AONUMA, T. MAYUMI, K. SUZUKI, T. NOGUCHI, M. IWAI AND M. OKABE}

Faculty of Pharmaceutical Sciences, Osaka University, Toneyama, Toyonaka, Osaka, Japan

(Received 2nd October 1972)

\begin{abstract}
Summary. During incubation of guinea-pig spermatozoa in Ca-free Krebs-Ringer phosphate buffer, substances were released into the medium which were subsequently separated on Sephadex G-200 into two major fractions, Fr. I and Fr. II.

The macromolecular Fr. I increased with sperm maturation and the fraction was shown to possess four different antigens. The amount of Fr. I. released from spermatozoa during incubation in the uterus was apparently influenced by the hormonal environment of the female reproductive tract. The fraction showed decapacitating activity, and decapacitated spermatozoa treated with Fr. I were capable of recapacitation after a second uterine incubation period. It was concluded that Fr. I was the decapacitation factor in guinea-pig semen.
\end{abstract}

\section{INTRODUGTION}

Chang (1951) and Austin (1951) have shown that rabbit spermatozoa must be present in the reproductive tract of the female in oestrus for several hours before ovulation to acquire fertilizing ability. Austin (1952) termed this phenomenon 'capacitation'.

The results of subsequent studies have suggested that a similar process may take place in the rat (Austin, 1951), hamster (Chang \& Sheaffer, 1957), ferret (Chang \& Yanagimachi, 1963) and cat (Hamner \& Jennings, 1970). Chang (1957) demonstrated that the fertilizing capacity of rabbit spermatozoa could be inhibited by seminal plasma or epididymal fluid (Weinman \& Williams, 1964) and termed this phenomenon 'decapacitation', and Bedford \& Chang (1962) were able to eliminate the decapacitation factor from seminal plasma. Dukelow, Chernoff, Pinsker \& Williams (1966) suggested that the decapacitation factor consisted of a protein-carbohydrate complex bound to the sperm head by sialic acid units. A sperm-coating antigen has been investigated in the guinea-pig (Henle \& Henle, 1940; Katsh \& Colo, 1959), rat (Isojima \& Li, 1968), mouse (McLaren, 1964; Bell, 1969) and rabbit (Weil, 1960).

By means of immunofluorescent techniques, Weil \& Rodenburg (1962) 
showed that sperm-coating antigens were present as a very thin layer on the surface of ejaculated spermatozoa.

Recently, Hunter \& Nornes (1969) recognized that a sperm-coating antigen isolated from rabbit seminal plasma possessed the ability to block fertilization. Furthermore, Isojima \& Ashitaka (1964) reported that some sperm antigens might be absorbed from the vagina or cervix to induce antibody production and studied the inhibition of fertility in the female guinea-pig. These facts suggest that a sperm-coating antigen may be released from the spermatozoa in the female reproductive tract and that such a phenomenon has some relationship to the sperm capacitation process.

The principal object of the present study was to prepare the antigenic product released from the guinea-pig epididymal spermatozoa and compare the amount of the product released at different maturation stages of the spermatozoa. A further object was to determine the amount of the product released from the spermatozoa during the incubation period in the oestrogen or progesterone-dominated female reproductive tract, and to assay the decapacitating activity of the released substance.

\section{MATERIALS AND METHODS}

\section{Preparation of sperm suspension}

Five male guinea-pigs weighing 600 to $700 \mathrm{~g}$ were killed by being bled from their carotid arteries immediately after being stunned.

The cauda epididymidis was quickly removed and divided into proximal and distal parts. The spermatozoa from the former were regarded as 'unripe' (or immature) spermatozoa and those from the latter as 'ripe'. Both parts were minced separately with iridectomy scissors, the spermatozoa were suspended in Ca-free Krebs-Ringer phosphate buffer (KRP buffer, pH 7.4) and the suspension was strained through cotton gauze. The filtered spermatozoa were centrifuged (1500 rev/min for $15 \mathrm{~min}$ ) and washed twice with buffer.

\section{Preparation of the substances released from guinea-pig spermatozoa}

Samples of ripe and unripe spermatozoa $\left(1 \times 10^{7}\right)$ were incubated in $3.0 \mathrm{ml}$ KRP buffer for 1,3 and $6 \mathrm{hr}$. The suspensions were centrifuged $(10,000 \mathrm{rev} / \mathrm{min}$ for $10 \mathrm{~min}$ ) and the u.v. spectra of the supernatants were measured with a Beckman UV spectrophotometer. The supernatants incubated for $6 \mathrm{hr}$ were applied to a Sephadex G-200 column $(2 \times 70 \mathrm{~cm})$ and eluted by distilled water (pH 7.4). The first peak (Fr. I) was used for immunological experiments.

\section{Immune sera and immunological tests}

An emulsification of $2 \mathrm{mg}$ Fr. I with $1.0 \mathrm{ml}$ complete Freund's adjuvant was prepared and the mixture was injected intramuscularly into the backs of rabbits twice weekly for 4 weeks. The anti-Fr. I serum obtained 2 weeks after the last injection was incubated with the residue $(20 \mathrm{mg})$ of the combined homogenate of kidney and liver at $37^{\circ} \mathrm{C}$ for $60 \mathrm{~min}$ and was then centrifuged at 10,000 $\mathrm{rev} / \mathrm{min}$ for $30 \mathrm{~min}$ to remove the non-specific antibody.

The supernatant was fractionated with ammonium sulphate, and the fraction of 20 to $50 \%$ saturation was dialysed and freeze-dried. This fraction was 
referred to as the specific immunoglobulin against Fr. I. As tissue antigens, the supernatant of a $5 \%$ homogenate of liver, kidney, testis, prostate, seminal vesicle, thymus and spleen was prepared. The antigen of the epididymal fluid was prepared from the supernatant which was separated following centrifugation of the sperm suspension.

The procedures for the Ouchterlony technique and immunoelectrophoresis were identical to those described by Hunter \& Hafs (1964).

\section{Determination of the binding ability of $\left[{ }^{131} I\right]$ anti-Fr. I immunoglobulin to epididymal spermatozoa}

Preparations of ${ }^{131} \mathrm{I}$-labelled anti-Fr. I immunoglobulin were produced according to the method of Greenwood, Hunter \& Glover (1963). The specific activity of $\left[{ }^{131} \mathrm{I}\right]$ anti-Fr. I immunoglobulin was $10 \mu \mathrm{Ci} / \mu \mathrm{g}$.

The freshly collected guinea-pig epididymal spermatozoa were treated as follows: (1) untreated; (2) incubated in an oestrogen-dominated uterus for $6 \mathrm{hr}$; (3) incubated in a progesterone-dominated uterus for $6 \mathrm{hr}$; (4) incubated in an oestrogen-dominated uterus for $6 \mathrm{hr}$ and then incubated in 5\% semen homogenate for $30 \mathrm{~min}$; (5) incubated in KRP buffer for $6 \mathrm{hr}$.

Female guinea-pigs, weighing $400 \mathrm{~g}$, were injected subcutaneously with oestradiol-17 $\beta$ or progesterone ( $150 \mu \mathrm{g} /$ day) for 2 weeks.

About $1 \times 10^{8}$ spermatozoa $/ 0.2 \mathrm{ml}$ of the epididymal sperm suspension were inseminated into both uterine horns and the spermatozoa were recovered with a syringe after $6 \mathrm{hr}$. The spermatozoa $\left(1 \times 10^{7} / 2 \cdot 0 \mathrm{ml}\right)$ were incubated with $\left[{ }^{131} \mathrm{I}\right]$ anti-Fr. I immunoglobulin $(5 \mu \mathrm{g})$ and non-labelled anti-Fr. I. immunoglobulin $(500 \mu \mathrm{g})$ at $37^{\circ} \mathrm{C}$ for $12 \mathrm{hr}$. They were then centrifuged at $3000 \mathrm{rev} / \mathrm{min}$ for $15 \mathrm{~min}$ and washed twice with buffer.

The radioactivity of the spermatozoa bound with $\left[{ }^{131} \mathrm{I}\right]$ anti-Fr. I immunoglobulin was measured by a well-type scintillation counter.

\section{The bioassay for decapacitation and recapacitation activity}

The bioassay for decapacitation and recapacitation activity in Fr. I was carried out by the same procedure as that described by Dukelow (1971) using rabbits, since the activity of the decapacitation factor did not show speciesspecificity among mammals. Mature female rabbits as ovum donors and recapacitators were injected intramuscularly with 150 i.u. PMSG to induce the growth of a large number of follicles and $72 \mathrm{hr}$ later, they were injected intravenously with 75 i.u. HCG to induce ovulation. Six hours after the artificial insemination of epididymal spermatozoa into the capacitator uterus, the spermatozoa were recovered and were incubated with Fr. I ( $\mathrm{l} \mathrm{mg} / 10^{7}$ spermatozoa) for $30 \mathrm{~min}$ at $37^{\circ} \mathrm{C}$. The treated spermatozoa were replaced into the oviduct $\left(1 \times 10^{7}\right.$ spermatozoa $\left./ 50 \mu \mathrm{l}\right)$ of the ovum donor and into the recapacitor uterus. The ova were recovered $24 \mathrm{hr}$ later and observed for the phase of cell cleavage.

\section{RESULTS}

The substances released from spermatozoa

The substances released from guinea-pig spermatozoa $\left(1 \times 10^{7} / 3 \mathrm{ml}\right)$ into the medium increased during incubation (Text-fig. 1). 
The ripe spermatozoa released larger amounts than the unripe.

The maximum u.v. absorption of the substances released occurred at about $273 \mathrm{~m} \mu$. Following column chromatography on Sephadex G-200 (Text-fig. 2), Fr. I and Fr. II gave maximum absorptions of $273 \mathrm{~m} \mu$ and $275 \mathrm{~m} \mu$, respectively. The two fractions from the ripe spermatozoa coincided with those from the unripe in terms of their elution volumes $(40 \mathrm{ml}$ and $110 \mathrm{ml})$.

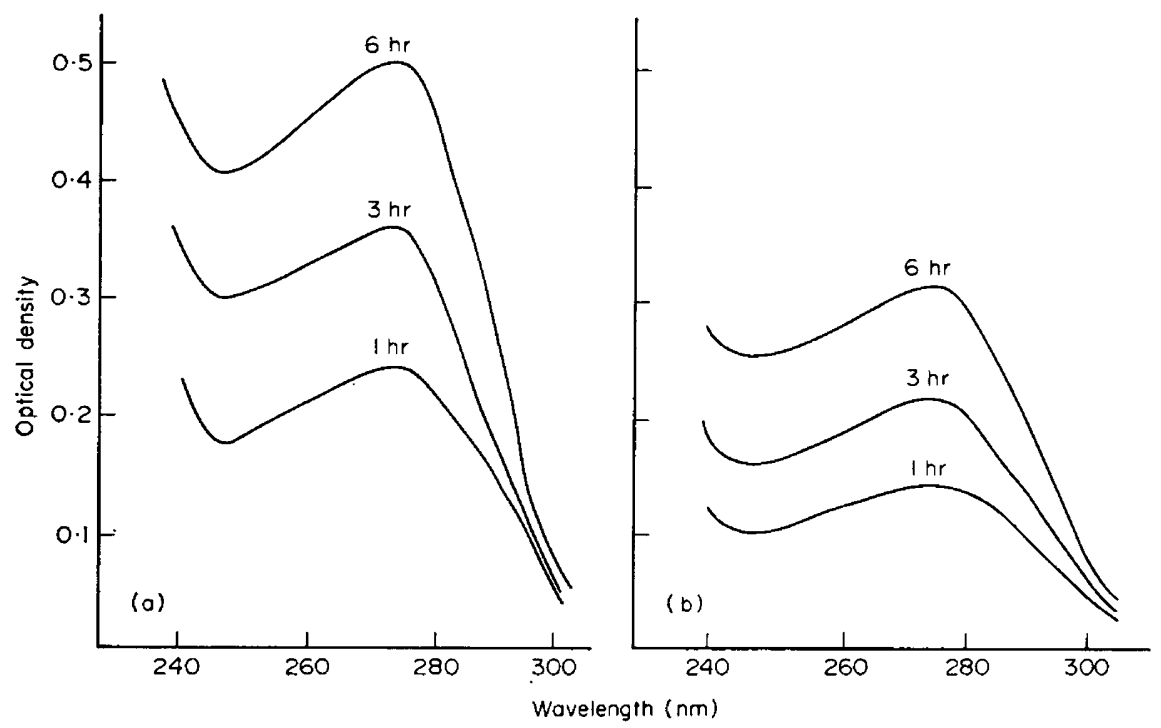

TEXT-FIG. 1. Ultraviolet spectra of the substance released from ripe (a) and unripe (b) guinea-pig spermatozoa. $\lambda_{\max }=273 \mathrm{~nm}$.

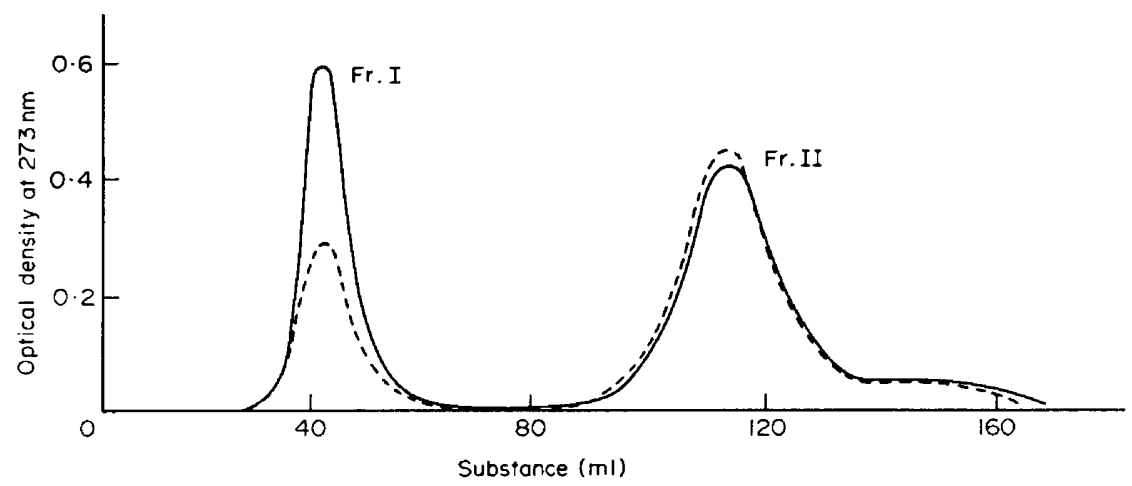

TExT-Fig. 2. Column chromatography on Sephadex G-200 of the substance released from incubated guinea-pig spermatozoa. (Column size, $2 \times 70 \mathrm{~cm}$; eluate, distilled water, $\mathrm{pH}$ 7.4.) -, Ripe spermatozoa; - - -, unripe spermatozoa.

\section{Immunological test}

The immunological characterization of Fr. I was summarized in Pl. 1, Figs 1 and 2 and Pl. 2, Fig. 3. Samples of Fr. I produced a cross-reaction with the reproductive tract tissue but not with other organs. The immunoelectro- 


\section{PI.ATE 1}
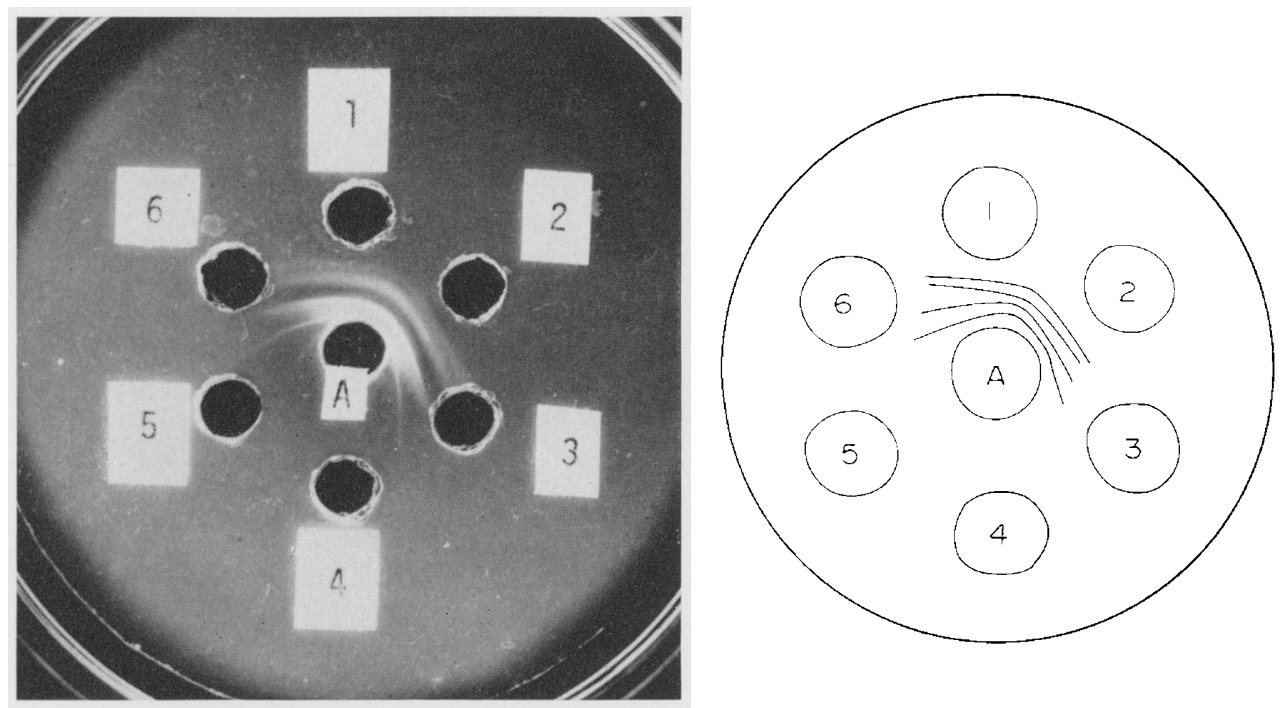

I
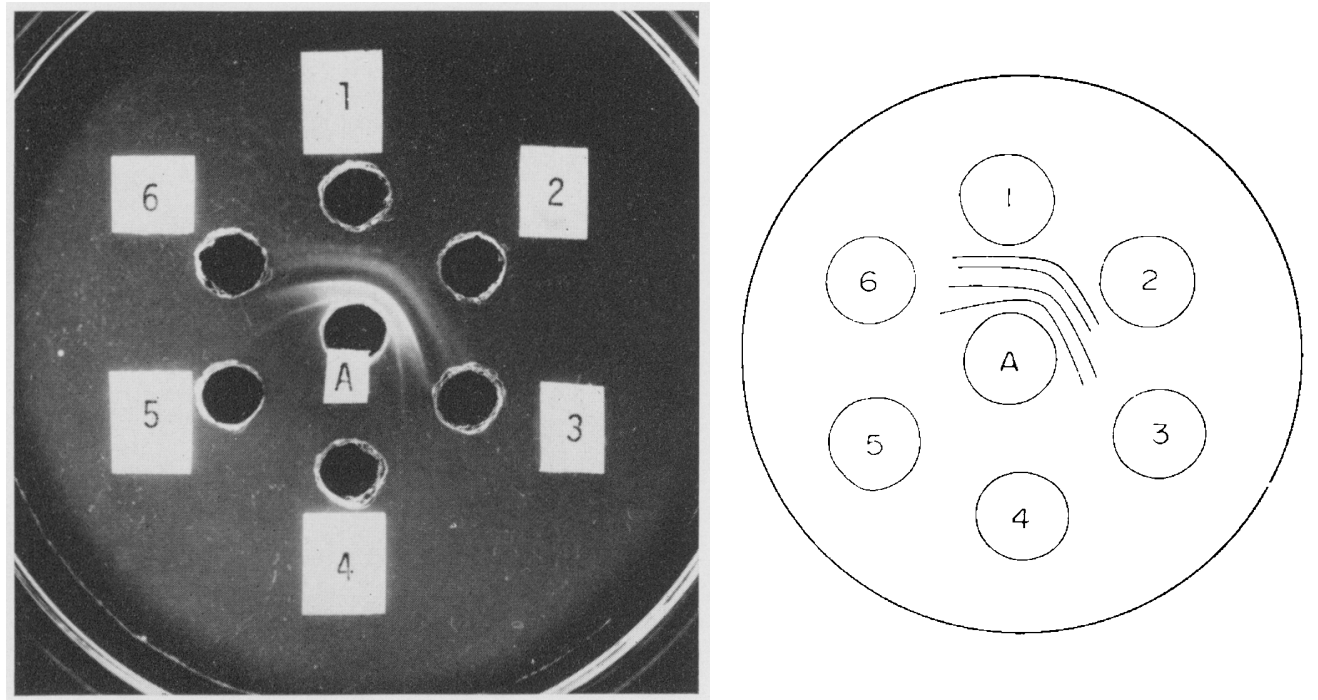

2

Figs 1 and 2. Agar-gel diffusion test of antigens from various male guinea-pig tissues to anti-Fr. I immunoglobulin. $\mathrm{A}=$ anti-Fr. I immunoglobulin. Fig. $1: 1=$ Fr. I; $2=$ testis; $3=$ thymus $;=$ spleen $5=$ prostate $;=$ liver. Fig. $2: 1=$ semen; $2=$ epididymal fluid; $3=$ seminal resicle fluid; $4=$ submaxillary gland; $5=$ kidney; $6=$ gastrocnemius musele. 
PLATE 2
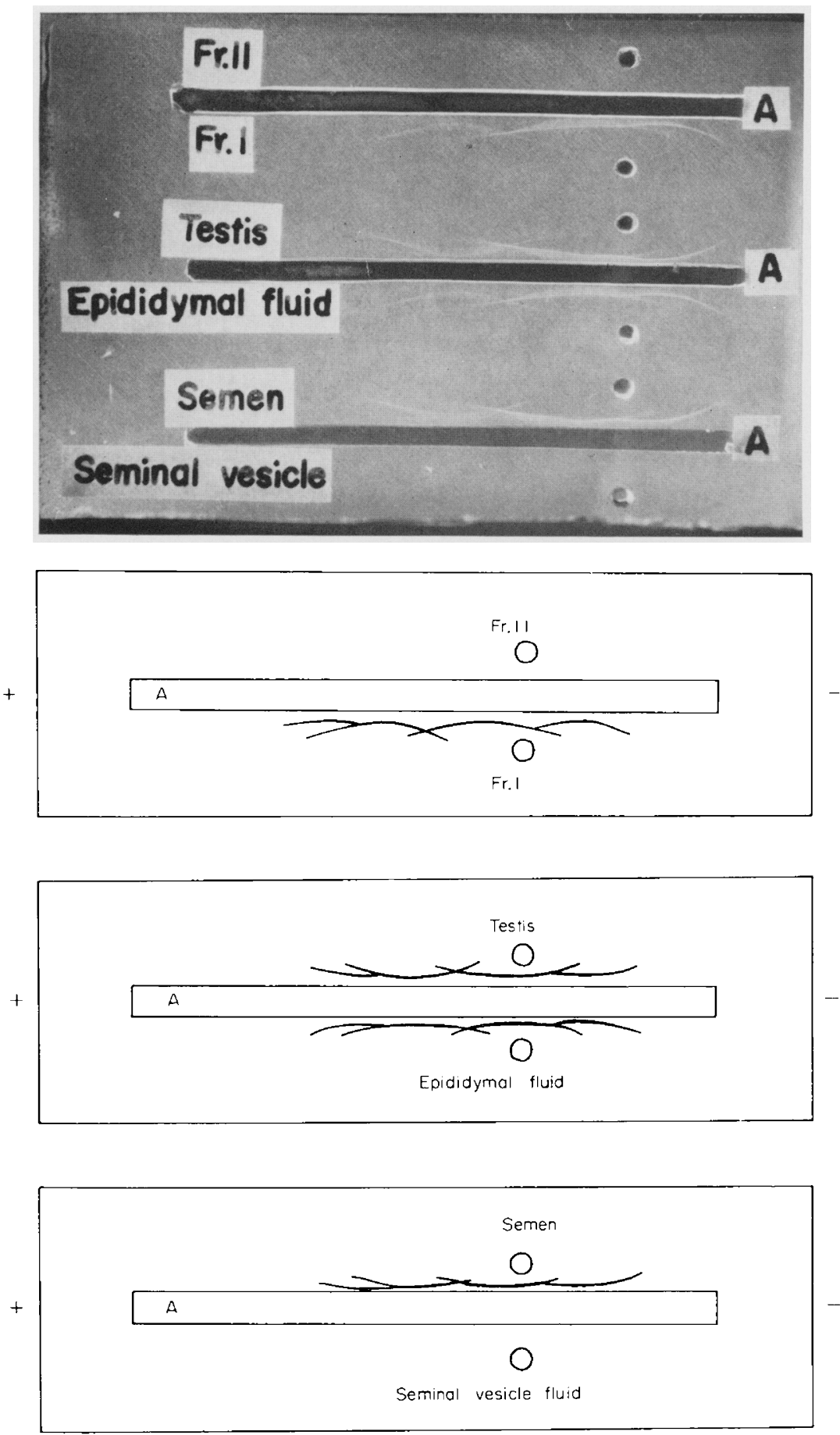

FIG. 3. Immunoelectrophoresis of antigens from various male guinea-pig tissues to antiFr. I immunoglobulin. A = anti-Fr. I immunoglobulin. 
phoresis data (Pl. 2, Fig. 3) showed that Fr. 1 had four different antigens and the samples from the testis, epididymal fluid and semen possessed the same four antigenicities, indicating that Fr. 1 was derived from the testis. To determine how Fr. 1 was influenced by the hormonal environment of the female reproductive tract, the binding ability of $\left[{ }^{131} \mathrm{I}\right]$ anti-Fr. I immunoglobulin to spermatozoa subjected to various treatments was studied. As shown in Table 1, the binding ability of immunoglobulin to spermatozoa incubated in an oestrogendominated uterus for $6 \mathrm{hr}$ was significantly reduced by about $30 \%$ compared with that of the fresh epididymal spermatozoa.

Table 1. Binding activity of $\left[{ }^{131} \mathrm{I}\right]$ anti-Fr. I immunoglobulin to guineapig spermatozoa

\begin{tabular}{|c|c|c|}
\hline Treatment & $\begin{array}{l}\text { Radioactivity } \$ \\
\left(\text { ct. } / \text { min } / 10^{7} \text { sperm. }\right) \\
(\text { Mean } \pm \text { S.E. })\end{array}$ & $\begin{array}{c}\text { Specific activity } \\
(\%)\end{array}$ \\
\hline $\begin{array}{l}\text { Uterine sperm. } \dagger \text { (capacitated sperm.) } \\
\text { Uterine sperm. treated with seminal plasma } \\
\text { (decapacitated sperm.) }\end{array}$ & $\begin{array}{l}2400 \pm 69^{*} \\
3127 \pm 13\end{array}$ & $\begin{array}{l}69 \\
90\end{array}$ \\
\hline $\begin{array}{l}\text { Uterine sperm. } \ddagger \text { (non-capacitated sperm.) } \\
\text { Epididymal sperm. (in vitro) } \\
\text { Epididymal sperm. (fresh) }\end{array}$ & $\begin{array}{l}2811 \pm 39 * * \\
2973 \pm 31 \\
3467 \pm 157\end{array}$ & $\begin{array}{r}81 \\
86 \\
100\end{array}$ \\
\hline
\end{tabular}

† Incubated in an oestrogen-dominated uterus for $6 \mathrm{hr}$.

Incubated in a progesterone-dominated uterus for $6 \mathrm{hr}$.

$\$$ The radioactivity of the spermatozoa washed by the buffer, after the reaction with [131I]anti-Fr. I immunoglobulin.

$* P<0.05, * * P<0.01$; significantly different compared to the group of fresh epididymal spermatozoa.

Table 2. Effect of Fr. I on the fertilization of rabbit spermatozoa

\begin{tabular}{l|c|c|c}
\hline \multicolumn{1}{c|}{ Treatment } & No. of ova & $\begin{array}{c}\text { No. of ova } \\
\text { fertilized }\end{array}$ & \% fertile \\
\hline Capacitated sperm.* & 19 & 16 & $84 \cdot 2$ \\
Capacitated sperm.*+Fr.I $\dagger$ & 26 & 3 & $11 \cdot 5$ \\
Capacitated sperm.*+Fr. I $\dagger$ & 36 & 20 & $55 \cdot 6$ \\
+recapacitated in utero & 13 & 1 & $7 \cdot 7$ \\
Epididymal sperm. & 1 & \\
\hline
\end{tabular}

* Spermatozoa were capacitated in an oestrous rabbit uterus for $6 \mathrm{hr}$.

$\dagger$ Incubated for $30 \mathrm{~min}, 1 \mathrm{mg} \mathrm{Fr} . \mathrm{I} / 10^{7}$ spermatozoa.

The radioactivity of the spermatozoa treated in the progesterone-dominated uterus remained high. It seems that greater amounts of sperm-coating antigens are released from spermatozoa incubated in an oestrogen-dominated uterus than in a progesterone-dominated uterus. When the former spermatozoa were treated with seminal plasma, the binding activity was recovered though to a degree which was slightly less than the original level for epididymal spermatozoa. The data presented in Table 2 show that the fertility of capacitated spermatozoa was reduced almost to the level of epididymal spermatozoa by treatment with 
Fr. I. The spermatozoa decapacitated with Fr. I were capable of significant recapacitation after a second uterine incubation period. These results suggest strongly that Fr. I is the guinea-pig decapacitation factor.

\section{DISGUSSION}

The present study represents the first biochemical approach to the physiological rôle of the substances which are released from spermatozoa during incubation. The level of Fr. I, which was highly antigenic, varied quantitatively with the different maturation stages of epididymal spermatozoa in guineapigs.

This suggests that the antigenic materials on the surface of the spermatozoa change quantitatively during passage through the epididymis or (/and) the sperm membrane configuration changes. The evidence that a decapacitation factor exists in bovine epididymal fluid (Hunter \& Hafs, 1964) suggests that the plasma membrane of bovine spermatozoa is coated with decapacitation factor in the epididymal tissue and that the factor is released when the spermatozoa are suspended in the medium.

It was reported by Bedford (1965) that rabbit spermatozoa begin to acquire their fertilizing ability in the middle segment of the corpus epididymidis, and the same phenomenon has also been observed in guinea-pigs (Young, 1931) and rats (Blandau \& Rumery, 1964).

Recently, Overstreet (1970) concluded that the process of sperm capacitation is primarily a continuation of the maturation process begun in the epididymis.

In the present study, Fr. I which was related to the maturation process of guinea-pig spermatozoa had high decapacitating activity. Decapacitation factor would, therefore, appear to be already bound to the epididymal spermatozoa in the epididymal tissue. As shown in Table 1, the binding ability of $\left.{ }^{\left[{ }^{131}\right.} \mathrm{I}\right]$ anti-Fr. I immunoglobulin to the spermatozoa subjected to various different treatments was influenced by the hormonal environment of the female reproductive tract. Since capacitation is more easily acquired in an oestrogenthan in a progesterone-dominated uterus, it seems that Fr. I plays an important rôle in the capacitation process of guinea-pig spermatozoa. When spermatozoa incubated in an oestrogen-dominated uterus (capacitated spermatozoa) were treated with Fr. I, the sperm-coating antigen bound to the plasma membrane of the capacitated spermatozoa thus inhibiting their fertilizing ability. The same spermatozoa were capable of undergoing significant recapacitation after a second uterine incubation period. These phenomena coincide with the assumption that the capacitation process constitutes the removal of a coating, possibly decapacitation factor, from the sperm surface.

The decapacitation process constitutes the surface binding of decapacitation factor, which originates in the spermatozoon itself, to mask a receptor site or in some other way to stabilize the sperm surface, and thus prevent the acrosome reaction. It is still uncertain whether the guinea-pig spermatozoa need to undergo the capacitation process to acquire fertilizing ability. We have recently noted, however, that guinea-pig spermatozoa incubated in an oestrogendominated uterus for $9 \mathrm{hr}$ have significantly high respiration and anaerobic 
fructolysis rates compared with spermatozoa incubated in a progesteronedominated uterus (S. Aonuma and co-workers, unpublished data). Bedford (1970) reported that the changes in the energy metabolism of spermatozoa in the female reproductive tract closely reflect permeability changes in their plasma membrane, which thereby allow substrates and ions to pass more freely. Such changes may be associated with capacitation. Consequently, guinea-pig spermatozoa do seem to require to undergo a capacitation process in the female reproductive tract before they can penetrate into the ova. Finally, the evidence from this study supports the view that sperm capacitation is primarily a renewal of the maturation process begun in the male reproductive tract.

\section{REFERENCES}

Austin, C. R. (1951) Observation on the penetration of the sperm into mammalian egg. Aust. F. scient. Res. B, 4, 581 .

Austin, C. R. (1952) The capacitation of the mammalian sperm. Nature, Lond. 170, 326.

BEDFord, J. M. (1965) Development of the fertilizing ability of spermatozoa in the rabbit epididymis. 7. Reprod. Fert. 10, 286.

Bedford, J. M. (1970) Sperm capacitation and fertilization in mammals. Biol. Reprod. Suppl. 2, 128.

Bedford, J. M. \& ChANG, M. C. (1962) Removal of decapacitation factor from seminal plasma by high-speed centrifugation. Am. F. Physiol. 202, 179.

BELL, E. B. (1969) Immunological control of fertility in the mouse; a comparison of systemic and intravaginal immunization. F. Reprod. Fert. 18, 183

Blandau, R. J. \& Rumery, R. E. (1964) The relationship of swimming movements of epididymal spermatozoa to their fertilizing capacity. Fert. Steril. 15, 571.

Chang, M. C. (1951) Fertilizing capacity of spermatozoa deposited into the Fallopian tubes. Nature, Lond. 168, 697.

Chang, M. C. (1957) A detrimental effect of seminal plasma on the fertilizing capacity of sperm. Nature, Lond. 179, 258.

Chang, M. C. \& Sheafrer, D. (1957) Number of spermatozoa ejaculated at copulation, transported into the female tract, and present in the male tract of the golden hamster. F. Hered. 48, 107.

Chang, M. C. \& Yanagmachi, R. (1963) Fertilization of ferret ova by deposition of epididymal sperm into the ovarian capsule with special reference to the fertilizable life of ova and the capacitation of sperm. F. exp. Zool. 154, 175.

Dukelow, W. R. (1971) Bioassay techniques related to sperm capacitation. Acta endocr., Copenh. 66, 503.

Dukelow, W. R., Chernofr, H. N., Pinsker, M. C. \& Williams, W. L. (1966) Enzymatic activities at the time of sperm capacitation. 7. Dairy Sci. 49, 725 (Abstr.).

Greenwood, F. G., Hunter, W. M. \& Glover, J. S. (1963) The preparation of ${ }^{131}$ I-labelled human growth hormone of high specific radioactivity. Biochem. 7. 89, 114.

Hamner, C. E. \& Jennings, L. L. (1970) Cat (Felis catus L.) spermatozoa require capacitation. $\mathcal{F}$. Reprod. Fert. 23, 477.

Hente, W. \& Hente, G. (1940) Spermatozoal antibodies and fertility. II. Attempt to induce temporary sterility in female guinea pig by active immunization against spermatozoa. 7 . Immun. 38, 105.

Hunter, A. G. \& HaFs, H. D. (1964) Antigenicity and cross-reactions of bovine spermatozoa. $\mathcal{F}$. Reprod. Fert. 7, 357.

Hunter, A. G. \& Nornes, H. O. (1969) Characterization and isolation of a sperm-coating antigen from rabbit seminal plasma with capacity to block fertilization. 7. Reprod. Fert. 20, 419.

Isojma, S. \& AshitakA, Y. (1964) Absorption of sperm antigen from the vagina in guinea pigs. Am. $\mathcal{J}$. Obstet. Gynec. 88, 433.

Isojima, S. \& LI, T. S. (1968) Stepwise appearance of sperm specific antigens in rats and their disappearance after fertilization. Fert. Steril. 19, 999.

KATsh, S. \& Colo, D. (1959) Infertility in female guinea pigs induced by injection of homologous sperm. Am. 7. Obstet. Gynec. 78, 276.

McLAREN, A. (1964) Immunological control of fertility in female mice. Nature, Lond. 201, 582.

Overstreet, J. W. (1970) Fertilizing capacity of epididymal spermatozoa. 7. Reprod. Fert. 21, 423.

WEIL, A. J. (1960) Immunological differentiation of epididymal and seminal spermatozoa of the rabbit. Science, N.Y. 131, 1040.

Weil, A. J. \& Rodenburg, J. M. (1962) The seminal vesicle as the source of the spermatozoa coating antigen of seminal plasma. Proc. Soc. exp. Biol. Med. 109, 567. 
Weinman, D. E. \& Williams, W. L. (1964) Mechanism of capacitation of rabbit spermatozoa. Nature, Lond. 203, 423.

Young, W. C. (1931) A study of the function of the epididymis. III. Functional changes undergone by spermatozoa during their passage through the epididymis and vas deferens in the guinea pig. $\mathcal{F}$. exp. Biol. 8, 151. 